\title{
ANALISIS STRATEGI PEMASARAN DALAM MENINGKATKAN PENJUALAN UDANG PADA PT. INDOMINA LANGGENG SEJAHTERA DI LAMPUNG SELATAN
}

\section{ANALYSIS OF MARKETING STRATEGIES IN INCREASING SHRIMP SALES AT PT. INDOMINA LANGGENG SEJAHTERA IN SOUTH LAMPUNG}

\author{
DEFRIZAL \\ Dosen Fakultas Ekonomi Universitas Bandar Lampung \\ Jl. Z.A Pagar Alam No. 26 Labuhan Ratu Bandar Lampung 35142 \\ Email: defrizal@ubl.ac.id
}

\author{
LUCKY RESTU IMANUEL NAIBAHO \\ Alumni Fakultas Ekonomi Universitas Bandar Lampung \\ Jl. Z.A Pagar Alam No. 26 Labuhan Ratu Bandar Lampung 35142 \\ Email: lucky.restu@ublstudent.ac.id
}

\begin{abstract}
Research entitled Analysis of Marketing Strategies in Increasing Shrimp Sales at PT.Indomina Langgeng Sejahtera in South Lampung has the purpose to determine the appropriate marketing strategy for companies to increase market share and to continue to exist amid ever-increasing business competition. This research deals with marketing strategies, which include strengths, weaknesses, opportunities, threats and market share owned and marketing strategies developed using SWOT analysis tools (Strengths, Weakness, Opportunities, Threats).Business development is now increasing from year to year, will automatically be coupled with increasing competition from business people, such as PT.Indomina Langgeng Sejahtera which was established in 2015 with a marketing strategy offering a variety of processed shrimp products.Based on the research conducted, it turns out that PT.Indomina Langgeng Sejahtera has advantages, based on IFAS and EFAS analysis, the results of the analysis show that the strength and weakness factor (IFAS) shows 2.65, and the opportunity and threat factor (EFAS) is 2.80 . Strength and opportunity factor (SO) of 3.80, strength and threat (ST) of 2.70, weakness and opportunity factor (WO) of 2.75, and for weakness and threat factor (WT) of 1.65.From the results of this analysis, it can be seen that PT.Indomina Langgeng Sejahtera has a great power to take advantage of opportunities and minimize threats. PT.Indomina Langgeng Sejahtera can also minimize weaknesses to take advantage of opportunities, moreover in minimizing weaknesses to avoid threats. Therefore PT.Indomina Langgeng Sejahtera can utilize its strengths and opportunities optimally.Keywords: Marketing strategy, SWOT and Sales
\end{abstract}

\begin{abstract}
ABSTRAK
Penelitian yang berjudul Analisis Strategi Pemasaran Dalam Meningkatkan Penjualan Udang Pada PT.Indomina Langgeng Sejahtera di Lampung Selatan memiliki tujuan untuk menentukan strategi pemasaran yang sesuai bagi perusahaan dalam meningkatkan pangsa pasar dan agar tetap terus eksis ditengah kompetisi usaha yang semakin meningkat. Penelitian ini berkenaan dengan strategi pemasaran, yang meliputi kekuatan, kelemahan, peluang, ancaman dan pangsa pasar yang dimiliki serta strategi pemasaran yang dikembangkan menggunakan alat analisis SWOT (Strengths, Weakness, Opportunities, Threats).Perkembangan bisnis kini semakin meningkat dari tahun ke tahun, secara otomatis akan dibarengi dengan semakin meningkatnya persaingan dari para pelaku bisnis, seperti PT.Indomina Langgeng Sejahtera yang didirikan sejak tahun 2015 dengan strategi pemasaran menawarkan variasi dari produk olahan udang.Berdasarkan penelitian yang dilakukan ternyata PT.Indomina Langgeng Sejahtera memiliki keunggulan, berdasarkan analisis IFAS dan EFAS dari hasil analisis tersebut menunjukan bahwa untuk faktor kekuatan dan kelemahan (IFAS) menunjukan angka 2,65, dan faktor peluang dan ancaman (EFAS) sebesar 2,80. Faktor kekuatan dan peluang (SO) sebesar 3,80, kekuatan dan ancaman (ST) sebesar 2,70, faktor kelemahan dan peluang (WO) sebesar 2,75, dan untuk faktor kelemahan dan ancaman (WT) sebesar 1,65.Dari hasil analisis
\end{abstract}


tersebut, dapat diketahui bahwa PT.Indomina Langgeng Sejahtera memiliki kekuatan yang besar untuk memanfaatkan peluang dan meminimalisir ancaman. PT.Indomina Langgeng Sejahtera juga dapat meminimalkan kelemahan untuk memanfaatkan peluang, terlebih lagi dalam meminimalkan kelemahan untuk menghindari ancaman. Oleh karena itu PT.Indomina Langgeng Sejahtera dapat memanfaatkan kekuatan dan peluang secara optimal.Kata kunci : Strategi pemasaran, SWOT dan Penjualan

\section{PENDAHULUAN}

Dalam keadaan perekonomian yang semakin sulit ini banyak terjadi persaingan di berbagai bidang kehidupan, termasuk didalamnya persaingan dalam dunia bisnis. Banyak perusahaan yang saling berlomba untuk mendapatkan pangsa pasar, sehingga hal ini memacu perusahaan untuk berusaha terus maju dalam memperbaiki bisnisnya. Perusahaan tentu akan berupaya untuk memenuhi harapan dan kebutuhan konsumen semaksimal mungkin sehingga akan menciptakan hubungan yang baik antara perusahaan dan pelanggannya. Hubungan ini dapat terjalin dan terus meningkat apabila perusahaan selalu memberikan pelayanan, produk, dan harga terbaik kepada konsumen.

PT. Indomina Langgeng Sejahtera yang beralamat di Jalan Insinyur Sutami, Kali Asin, Kec. Tj. Bintang, Kabupaten Lampung Selatan, Lampung merupakan bisnis yang bergerak dibidang pengolahan udang yang dipasarkan secara online. Agar dapat bersaing, perusahaan harus dituntut untuk kreatif dalam melakukan promosi dan mempertahankan serta menambah segi kualitas.

Perusahaan ini berdiri sejak tahun 2015 sebagai perusahaan pengolahan udang dengan jumlah karyawan kurang lebih 1500 orang. Juga memiliki kantor representatif yang berada di L'Agricola Blok B.2, Jalan Curug Sangerang, Kota Tangerang Selatan. Perusahaan ini menganut prinsip GMP (Good Manufacturing Practices) dan SSOP (Standard Sanitation Operating Procedures) yang mana prasyarat programnya untuk HACCP (Hazard Analysis Critical Control Point) program untuk panen, angkutan untuk processing plant, pengolahan, untuk menyelesaikan produk. Proses ini memastikan bahwa produk tersebut menggunakan standar untuk kualitas dan keamanan dalam segi makanannya. Berikut adalah contoh produk dan harga yang dapat kita lihat pada tabel 1.1 di bawah ini :

Tabel 1.1 Nama Produk dan Harga yang di Jual oleh PT. Indomina Langgeng Sejahtera

\begin{tabular}{|l|c|c|}
\hline No. & Nama Produk & Harga / Kg \\
\hline 1 & Frozen Indonesian Monodon Shrimp Headless 062 225.505 \\
\hline 2 & Frozen Indonesian Monodon Shrimp Easy Peel 065 & Rp. 243.272 \\
\hline 3 & Frozen Indonesian Vannamei PD Vacuum Pack 085 133.936 \\
\hline 4 & Frozen Indonesian Vannamei PDTO IQF & Rp. 125.000 \\
\hline 5 & Frozen Indonesian Vannamei PD Second Grade 82.000 \\
\hline 6 & Frozen Indonesian Vannamei Shrimp Broken & Rp. 59.000 \\
\hline
\end{tabular}

Sumber : PT.Indomina Langgeng Sejahtera

PT.Indomina Langgeng Sejahtera mengalami suatu masalah dengan terjadinya fluktuasi dan penurunan penjualan udang. Hal ini mungkin disebabkan karena kurang tepatnya strategi pemasaran yang dilakukan, seperti kurang memanfaatkan media sarana promosi selain hanya aktif melalui website perusahaan dan tidak pernah mengikuti kegiatan/acara yang memperkenalkan produk secara lebih luas. Untuk itu diperlukan strategi pemasaran yang tepat agar bisnis dapat meningkatkan penjualan produknya.

Dari permasalahan di atas, maka penulis tertarik melakukan penelitian secara lebih mendalam mengenai strategi pemasaran untuk meningkatkan penjualan dengan judul yaitu "Analisis Strategi 
Pemasaran Dalam Meningkatkan Penjualan Udang Pada PT.Indomina Langgeng Sejahtera di Lampung Selatan".

Rumusan masalah dikemukakan sebagai berikut:

1. Bagaimanakah strategi pemasaran yang harus dilakukan dalam meningkatkan penjualan pada

\section{TINJAUAN PUSTAKA}

Menurut Kotler ( 2004 ) "Strategi Pemasaran adalah pola pikir pemasaran yang akan digunakan untuk mencapai tujuan pemasarannya. Strategi pemasaran berisi strategi spesifik untuk pasar sasaran, penetapan posisi, bauran pemasaran dan besarnya pengeluaran pemasaran."

Banu Swatha (2010) menyatakan "Menjual adalah ilmu dan seni mempengaruhi pribadi yang dilakukan oleh penjual untuk mengajak orang lain agar bersedia membeli barang atau jasa yang ditawarkan." Berdasarkan penjelasan di atas dapat disimpulkan

\section{KERANGKA KONSEPTUAL}

Menurut Sugiyono (2012) mendefinisikan kerangka pemikiran adalah model konseptual tentang bagaimana teori berhubungan dengan berbagai faktor yang telah diidentifikasi sebagai masalah yang
PT.Indomina Langgeng Sejahtera di Lampung Selatan?

Tujuan penelitian dikemukakan sebagai berikut: untuk mengetahui strategi pemasaran yang tepat dalam meningkatkan penjualan pada PT.Indomina Langgeng Sejahtera.

bahwa " Penjualan merupakan pembelian sesuatu (barang atau jasa) dari suatu pihak lainnya dengan mendapatkan ganti uang dari pihak tersebut".

Rangkuti (2008:19) mengemukakan bahwa : "Analisis SWOT membandingkan antara faktor eksternal peluang (opportunities) dan ancaman (threats) dengan faktor internal kekuatan (strenghts) dan kelemahan (weaknesses)."

penting. Berdasarkan teori yang dikemukakan di tinjauan pustaka, maka peneliti mengembangkan kerangka pemikiran yang dapat dilihat seperti berikut ini:

Gambar 2.1 Kerangka Konseptual PT.Indomina Langgeng Sejahtera

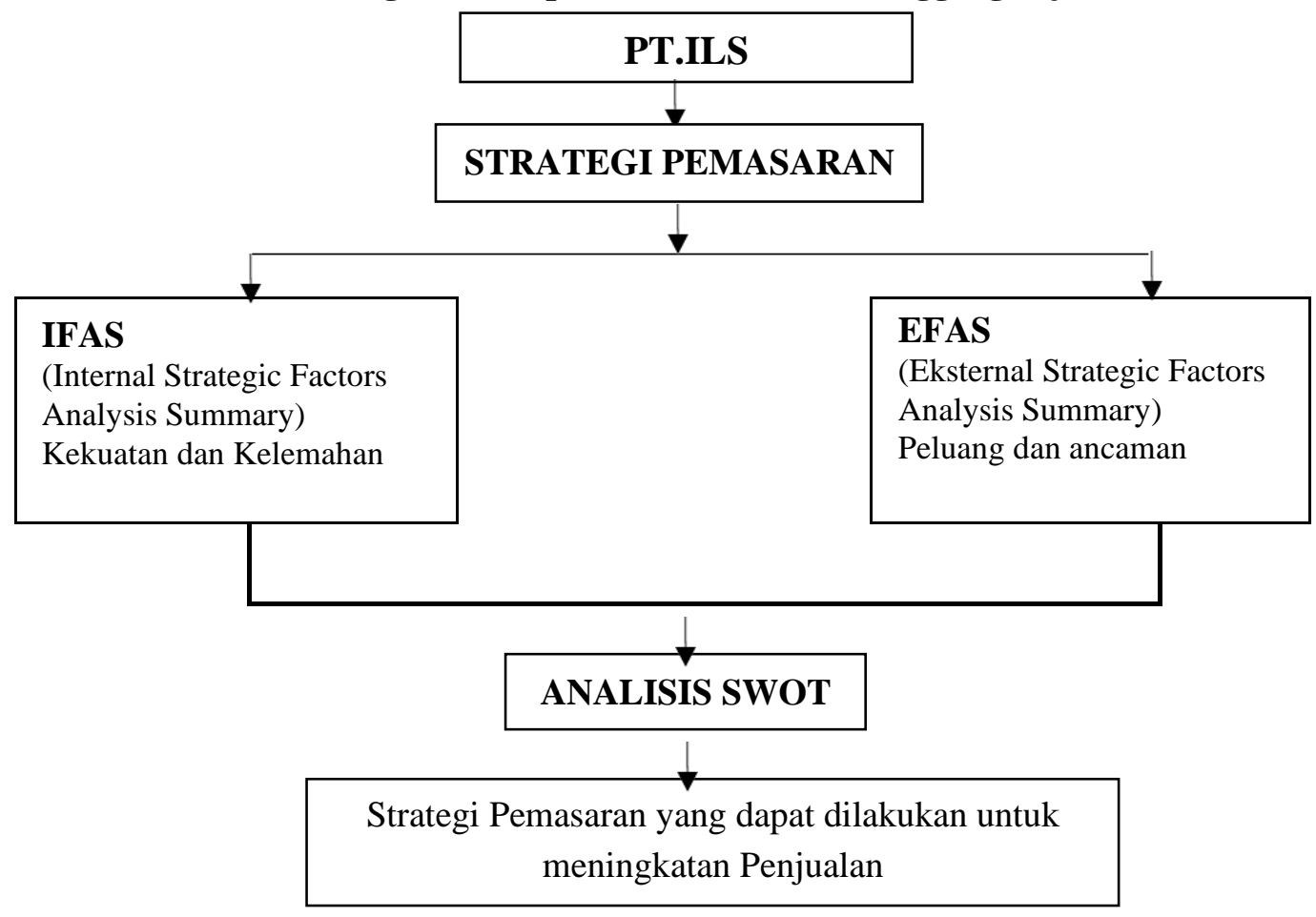




\section{METODE PENELITIAN}

\section{Analisis SWOT}

Alat analisis yang digunakan untuk membahas permasalahan dan mencari pemecahan dalam menganalisa strategi bersaing yaitu dengan menggunakan Analisis SWOT (Strength, Weakness,

\section{Prosedur Matrik SWOT}

Matriks ini menggambarkan secara jelas bagaimana peluang dan ancaman internal yang dihadapi dapat disesuaikan dengan kekuatan dan kelemahan internal
Opportunity, Threats). Metode ini merupakan metode yang berdasarkan pada kekuatan, kelemahan, peluang dan ancaman yang datang dari perusahaan maupun dari luar perusahaan atau pesaing.

yang dimiliki. Matrik ini dapat menghasilkan empat set kemungkinan alternatif strategis, seperti pada Tabel 4 berikut :

\section{Matriks SWOT}

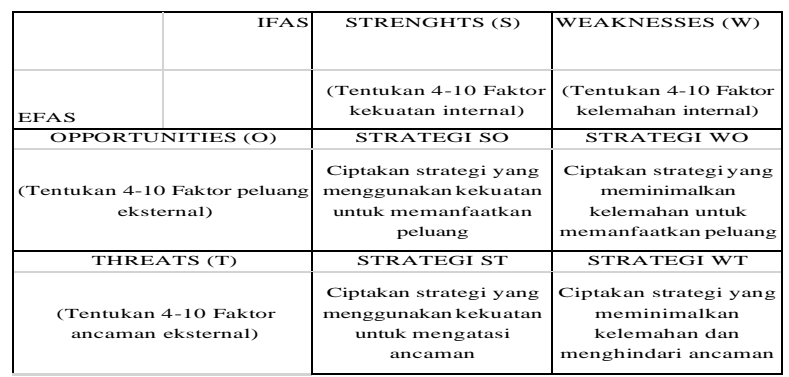

Sumber : Rangkuti, 2006

\section{EFAS}

Analisis faktor strategis eksternal difokuskan pada kondisi yang ada dan kecenderungan yang muncul dari luar, tetapi dapat memberi pengaruh kinerja organisasi. Setelah mengetahui faktor-faktor strategi eksternal, selanjutnya susun tabel faktor-faktor Strategis Eksternal ( External Strategic Factors Analysis Summary/EFAS ), dengan langkah sebagai berikut :

1. Menyusun faktor peluang dan ancaman pada kolom 1.

2. Memberikan bobot masing-masing faktor pada kolom 2, mulai dari 1,0 (sangat penting) sampai dengan 0,0 (tidak penting). Bobot dari semua faktor strategis yang berupa peluang dan ancaman ini harus berjumlah 1.

3. Menghitung rating dalam (dalam kolom 3) untuk masing-masing faktor dengan memberi skala mulai dari 4 (sangat baik/outstanding) sampai dengan 1 (sangat tidak baik/poor) berdasarkan pengaruh faktor tersebut pada kondisi perusahaan. Pemberian nilai rating untuk peluang bersifat positif, artinya peluang yang semakin besar diberi rating +4 , tetapi jika peluangnya kecil diberi nilai +1 . Sementara untuk rating ancaman bersifat sebaliknya, yaitu jika nilai ancamannya besar, maka ratingnya -4 dan jika nilai ancamannya kecil, maka nilainya -1 .

4. Mengalikan bobot faktor pada kolom 2 dengan rating pada kolom 3. Hasilnya adalah skor pembobotan untuk masingmasing faktor.

5. Menghitung jumlah skor pembobotan. Nilai ini adalah untuk memetakan posisi organisasi pada diagram analisa SWOT. 


\section{IFAS}

Analisis faktor strategis internal adalah analisis yang menilai prestasi/kinerja yang merupakan faktor kekuatan dan kelemahan yang ada untuk mencapai tujuan organisasi. Seperti halnya pada Analisis Faktor Strategis Eksternal, maka dengan cara yang sama menyusun tabel Faktor-faktor Strategis Internal (Internal Strategic Factors Analysis Summary/IFAS). Setelah mengetahui faktor-faktor strategi internal, selanjutnya susun tabel faktor-faktor Strategis Internal ( Internal Strategic Factors Analysis Summary/IFAS ), dengan langkah sebagai berikut :

1. Menyusun faktor peluang dan ancaman pada kolom 1.

2. Memberikan bobot masing-masing faktor pada kolom 2, mulai dari 1,0 (sangat penting) sampai dengan 0,0 (tidak penting). Bobot dari semua faktor strategis yang berupa peluang dan ancaman ini harus berjumlah 1.

\section{Matrik IE (Internal Eksternal)}

Matrik Internal Eksternal berfungsi untuk memposisikan suatu perusahaan kedalammatriks yang terdiri atas 9 sel. IE matrik terdiri atas dua
3. Menghitung rating dalam (dalam kolom 3) untuk masing-masing faktor dengan memberi skala mulai dari 4 (sangat baik/outstanding) sampai dengan 1 (sangat tidak baik/poor) berdasarkan pengaruh faktor tersebut pada kondisi perusahaan. Variabel yang bersifat positif (semua variabel yang masuk kategori kekuatan) diberi nilai mulai dari +1 sampai dengan +4 (sangat baik) dengan membandingkannya dengan rata-rata industri atau dengan pesaing utama. Sedangkan variabel yang bersifat negatif, kebalikannya.

4. Mengalikan bobot faktor pada kolom 2 dengan rating pada kolom 3. Hasilnya adalah skor pembobotan untuk masingmasing faktor.

5. Menghitung jumlah skor pembobotan. Nilai ini adalah untuk memetakan posisi organisasi pada diagram analisa SWOT.

dimensi, yaitu : total skor dari IFAS pada sumbu X dan total skor dari EFAS pada sumbu Y.

Tabel 3.2 Matrik IE (Internal Eksternal)

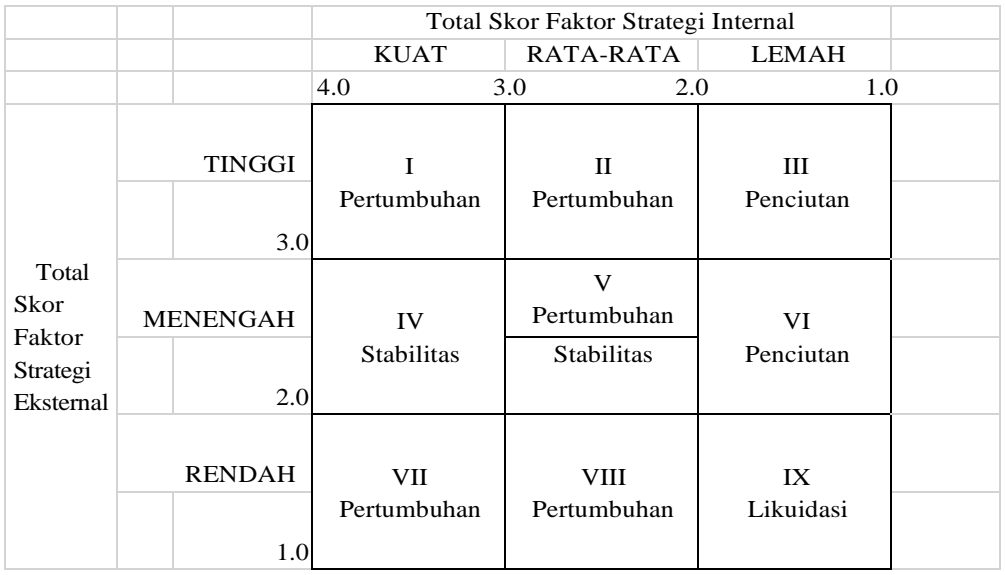




\section{HASIL ANALISIS DAN PEMBAHASAN}

\section{Analisis Internal (Internal Factors Analysis Summary)}

IFAS PT.Indomina Langgeng Sejahtera

\begin{tabular}{|c|c|c|c|c|}
\hline No & Faktor-faktor Internal & Bobot & Rating & Bobot x Rating \\
\hline \multicolumn{5}{|c|}{ Kekuatan } \\
\hline 1 & Kualitas produk baik & 0.20 & 3 & 0.60 \\
\hline 2 & Stok produk selalu ada & $\mathbf{0 . 2 0}$ & 3 & $\mathbf{0 . 6 0}$ \\
\hline 3 & Fasilitas perusahaan yang memadai & $\mathbf{0 . 1 0}$ & 2 & 0.20 \\
\hline 4 & Produk udang yang dijual bervariasi & 0.15 & 3 & 0.45 \\
\hline \multicolumn{2}{|r|}{ Sub Total } & 0.65 & & 1.85 \\
\hline \multicolumn{5}{|c|}{ Kelemahan } \\
\hline 1 & Kurangnya promosi & 0.10 & 2 & 0.20 \\
\hline 2 & Keterbatasan bahan baku & 0.15 & 2 & $\mathbf{0 . 3 0}$ \\
\hline 3 & Lokasi yang sulit dijangkau & 0.05 & 3 & 0.15 \\
\hline 4 & Harga yang tidak stabil & 0.05 & 3 & 0.15 \\
\hline \multicolumn{2}{|r|}{ Sub Total } & 0.35 & & $\mathbf{0 . 8 0}$ \\
\hline & Total & 1.00 & & 2.65 \\
\hline
\end{tabular}

Sumber : Data dioalah, 2020.

\section{Analisis Eksternal (Eksternal Factors Analysis Summary)}

EFAS PT.Indomina Langgeng Sejahtera

\begin{tabular}{|c|c|c|c|c|}
\hline No & Faktor-faktor Eksternal & Bobot & Rating & Bobot x Rating \\
\hline \multicolumn{5}{|c|}{ Peluang } \\
\hline 1 & Konsumen setia dalam membeli produk & 0.15 & 3 & 0.45 \\
\hline 2 & Konsumen sering membeli produk dalam jumlah banyak & 0.15 & 2 & $\mathbf{0 . 3 0}$ \\
\hline 3 & Hubungan yang baik dengan konsumen & 0.15 & 4 & 0.60 \\
\hline 4 & Memiliki banyak vendor & 0.15 & 4 & 0.60 \\
\hline \multicolumn{2}{|r|}{ Sub Total } & 0.60 & & 1.95 \\
\hline \multicolumn{5}{|c|}{ Ancaman } \\
\hline 1 & Memiliki banyak pesaing & 0.15 & 2 & 0.30 \\
\hline 2 & $\begin{array}{l}\text { Adanya kesamaan produk udang dengan perusahaan } \\
\text { lainnya }\end{array}$ & $\mathbf{0 . 1 0}$ & 2 & $\mathbf{0 . 2 0}$ \\
\hline 3 & Pesaing gencar melakukan promosi & 0.10 & 2 & 0.20 \\
\hline 4 & Lokasi pesaing yang lebih strategis & 0.05 & 3 & 0.15 \\
\hline \multicolumn{2}{|r|}{$\begin{array}{c}\text { Sub Total } \\
\end{array}$} & 0.40 & & 0.85 \\
\hline & Total & 1.00 & & 2.80 \\
\hline
\end{tabular}

Sumber : Data diolah, 2020. 


\section{IE PT. Indomina Langgeng Sejahtera}

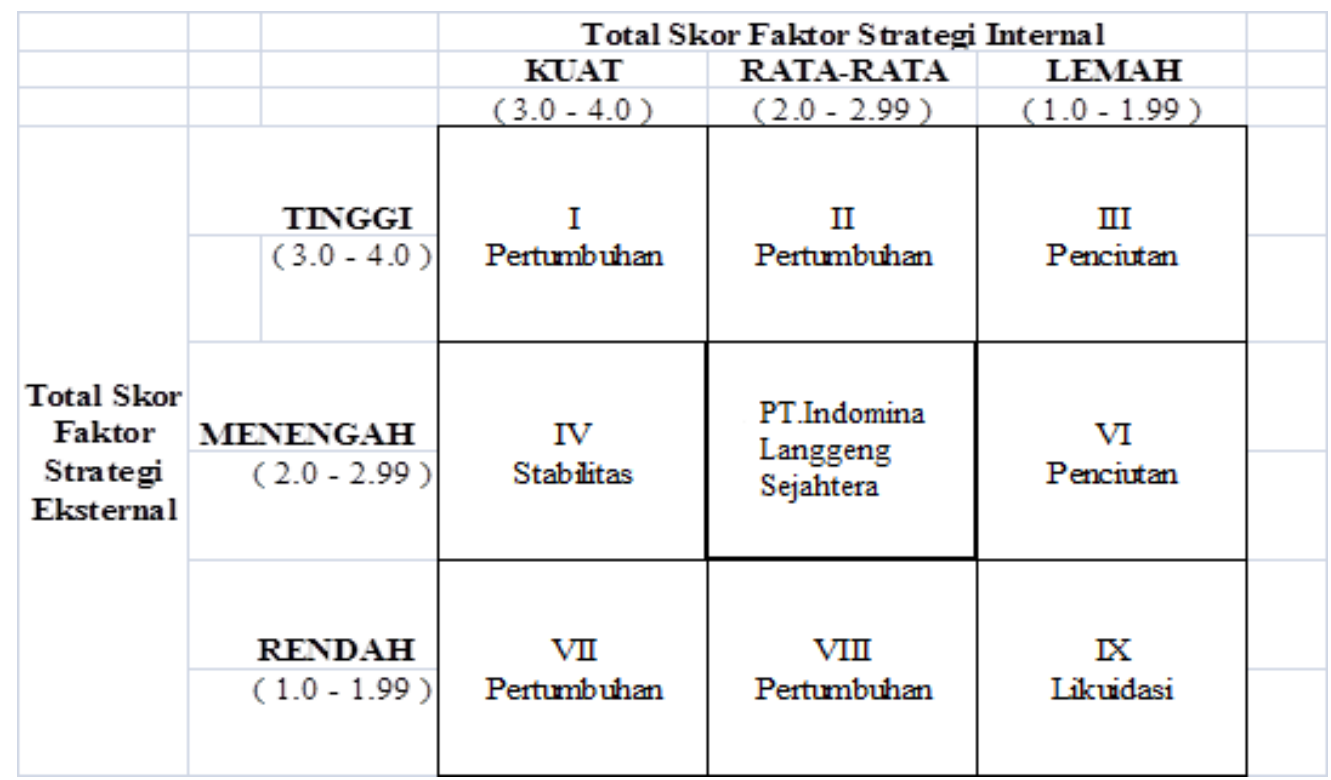

Sumber : Data diolah, 2020.

Tabel 4.8

Matrik SWOT PT. Indomina Langgeng Sejahtera

\begin{tabular}{|c|c|c|}
\hline$x$ & $\begin{array}{l}\text { Strength : } \\
\text { 1. Kualitas Produk yang baik } \\
\text { 2. Stok produk selalu ada } \\
\text { 3. Fasilitas perusahaan yang } \\
\text { memadai } \\
\text { 4. Produk udang yang dijual } \\
\text { bervariasi }\end{array}$ & $\begin{array}{l}\text { Weakness : } \\
\text { 1. Kurangnya promosi } \\
\text { 2. Keterbatasan bahan baku } \\
\text { 3. Lokasi yang sulit dijangkau } \\
\text { 4. Harga yang tidak stabil }\end{array}$ \\
\hline Opportunity: & Strategi SO : & Strategi WO : \\
\hline $\begin{array}{l}\text { 1. Konsumen yang setia } \\
\text { membeli produk }\end{array}$ & $\begin{array}{l}\text { 1. Perusahaan menjaga dan } \\
\text { menaikan kualitas produk agar } \\
\text { konsumen tetap nyaman }\end{array}$ & $\begin{array}{l}\text { 1. Melakukan promosi untuk } \\
\text { menarik minat konsumen lebih } \\
\text { banyak }\end{array}$ \\
\hline $\begin{array}{l}\text { 2.Konsumen sering membeli } \\
\text { produk dalam jumlah banyak } \\
\text { 3.Hubungan yang baik dengan } \\
\text { konsumen }\end{array}$ & $\begin{array}{l}\text { 2. Menjaga hubungan yang baik } \\
\text { dengan konsumen dengan cara } \\
\text { menyediakan produk yang selalu } \\
\text { tersedia }\end{array}$ & $\begin{array}{l}\text { 2. Memiliki tambak udang } \\
\text { perusahaan sendiri untuk } \\
\text { menjaga bahan baku produk }\end{array}$ \\
\hline 4.Memiliki banyak vendor & $\begin{array}{l}\text { 3. Memaksimalkan fasilitas } \\
\text { perusahaan agar konsumen } \\
\text { semakin puas dengan hasil dan } \\
\text { pelayanan perusahaan }\end{array}$ & $\begin{array}{l}\text { 3. Mencari lokasi yang mudah } \\
\text { dijangkau untuk menarik lebih } \\
\text { banyak konsumen. }\end{array}$ \\
\hline
\end{tabular}




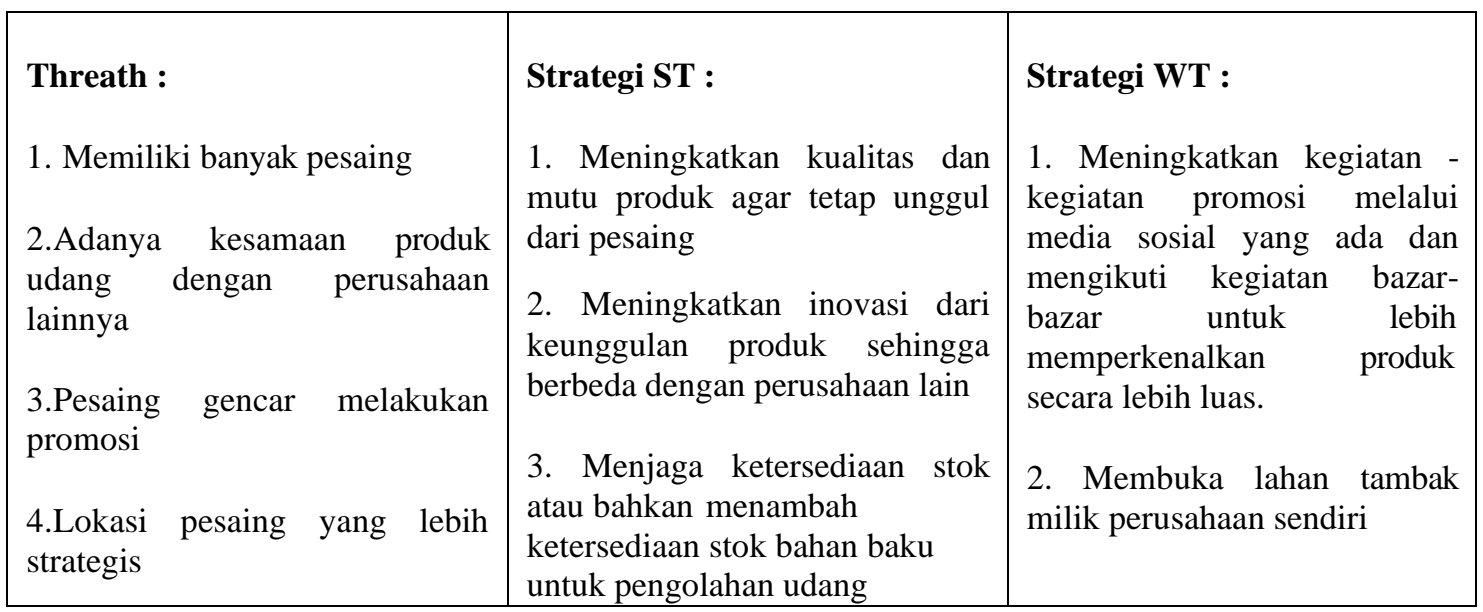

Sumber : Data diolah, 2020.

Tabel 4.9

Rumusan Kombinasi Matrik SWOT

\begin{tabular}{|c|c|c|}
\hline IFAS & Strength (S) & Weakness (W) \\
\hline Opportunity (O) & $\begin{array}{l}\text { Strategi (SO) } \\
=1.85+1.95 \\
=3.80\end{array}$ & $\begin{array}{l}\text { Strategi }(\text { WO }) \\
=0.80+1.95 \\
=2.75\end{array}$ \\
\hline Threat (T) & $\begin{array}{l}\text { Strategi }(\mathrm{ST}) \\
=1.85+0.85 \\
=2.70\end{array}$ & $\begin{array}{l}\text { Strategi }(\mathrm{WT}) \\
=0.80+0.85 \\
=1.65\end{array}$ \\
\hline
\end{tabular}

Sumber : Data diolah, 2020.

\section{KESIMPULAN}

Berdasarkan uraian dan pembahasan yang telah dikemukakan pada bab-bab sebelumnya maka dapat ditarik beberapa pokok-pokok yang menjadi kesimpulan dalam penulisan ini yaitu:

1. Strategi pemasaran yang dapat dilakukan oleh PT.Indomina Langgeng Sejahtera dalam meningkatkan penjualan adalah Strategi konsentrasi melalui integrasi horizontal. Artinya strategi yang diterapkan lebih defensif, yaitu menghindari kehilangan penjualan dan kehilangan profit yang di sebabkan oleh ancaman-ancaman seperti banyaknya pesaing yang menjual produk yang sama, pesaing gencar melakukan promosi.

2. Hasil Analisis SWOT antara lain :

a. Kekuatan yang dimiliki PT.Indomina Langgeng Sejahtera terletak pada:

1) Kualitas Produk
2) Stok Produk selalu ada

3) Fasilitas perusahaan yang memadai

4) Produk olahan udang yang dijual bervariasi

b. Kelemahan yang dimiliki PT.Indomina Langgeng Sejahtera terletak pada:

1) Kurangnya promosi

2) Keterbatasan bahan baku

3) Lokasi yang sulit dijangkau

4) Harga yang tidak stabil

c. Peluang yang dimiliki PT.Indomina Langgeng Sejahtera terletak pada:

1) Memiliki banyak konsumen yang setia

2) Konsumen sering membeli produk dalam jumlah banyak

3) Memiliki hubungan yang baik dengan konsumen

4) Memiliki vendor 
d. Ancaman yang ada pada PT.Indomina

Langgeng Sejahtera terletak pada :

1) Memiliki banyak pesaing

2) Adanya kesamaan produk udang dengan perusahaan lainnya

3) Pesaing gencar melakukan promosi

4) Lokasi pesaing yang lebih strategis

3. Berdasarkan hasil dari analisis SWOT strategi yang cocok dalam meningkatkan penjualan produk udang adalah startegi SO dan WO.

1. Strategi SO

a. Perusahaan menjaga dan menaikan kualitas produk agar konsumen tetap nyaman b. Menjaga hubungan yang baik dengan konsumen dengan cara menyediakan produk yang selalu tersedia

c. Memaksimalkan fasilitas perusahaan agar konsumen semakin puas dengan hasil dan pelayanan perusahaan

2. Strategi WO

a. Melakukan promosi untuk menarik minat konsumen lebih banyak

b. Memiliki tambak udang perusahaan sendiri untuk menjaga bahan baku produk

c. Mencari lokasi yang mudah dijangkau untuk menarik lebih banyak konsumen.

\section{Saran}

Dari hasil uraian dan pembahasan yang telah dikemukakan maka terdapat beberapa pokok saran yang dapat dipertimbangkan PT.Indomina Langgeng Sejahtera adalah sebagai berikut :

1. Dalam melakukan startegi pemasaran perusahaan hendaknya perlu membuat strategi pemasaran yang lebih baik dengan memperhatikan startegi yang telah dijalankan sebelumnya. Tetapi yang perlu diperhatikan adalah strategi menjaga dan menaikan kualitas produk yang diberikan.

2. Dari kesimpulan analisis SWOT hal-hal yang dapat dilakukan oleh pihak PT.Indomina Langgeng Sejahtera dalam

\section{DAFTAR PUSTAKA}

Indomina-ils.com

Alma, B.2004. Manajemen Pemasaran dan Pemasaran Jasa. Bandung:Alfabeta

Appley, A. Lawrence; Lee, Oey Liang. 2010.

Pengantar Manajemen. Jakarta: Salemba Empat.

Assauri, Sofyan. 2008. Manajemen Pemasaran Dasar, Konsep dan Strategi. Edisi Pertama. Cetakan Keempat. Penerbit Rajawali. Jakarta.

2008. Manajemen Pemasaran, edisi pertama, cetakan ke delapan,

Penerbit : Raja Grafindo, Jakarta

\section{Manajemen Pemasaran.}

Jakarta : Rajawali Pers. upaya meningkatkan nilai penjualan udang antara lain adalah dengan menjaga dan menaikan kualitas produk, menjaga hubungan baik dengan konsumen dan melakukan kegiatan-kegiatan promosi secara rutin, memaksimalkan fasilitas perusahaan, serta menjaga ketersediaan stok atau bahkan menambah ketersediaan stok produk dengan cara membangun tambak pribadi. Perusahaan juga harus mencari tenaga kerja yang relevan demi kenyamanan perusahaan.
Hasan, Ali. 2013. Marketing Dan KasusKasusPilihan. Yogyakarta: Caps

Kotler, Philip. 2004. Manajeme Pemasaran: Analisis, Perencanaan, implementasi dan Kontrol, Edisi Sebelas. Alih Bahasa, Hendra Teguh. Jakarta: Penerbit PT.Prenhallindo. 2005. Manajamen Pemasaran, Jilid 1 dan 2. Jakarta: PT. Indeks Kelompok Gramedia.

Kotler, Philip dan Armstrong, Gary. 2012. Principles of Marketing. New Jersey: Prentice Hall.

Kotler, Philip dan Kevin Lane keller. 2009. Manajemen PemasaranEdisis 13 Jilid 1. Jakarta: PT.Indeks.

1. Edisike 13. Diterjemahkan 
oleh: Bob Sabran. Jakarta: Erlangga

Munadi, Fandi Ahmad.2009. Analisis Strategi

Pemasaran Untuk Meningkatkan Penjualan

Kendaraan Motor CV. Turangga Mas Motor

Rangkuti, Freddy. 2006. Analisis SWOT : Teknik Membedah Kasus Bisnis, Penerbit PT Gramedia Pustaka Utama: Jakarta

Membedah KasusBisnis. Jakarta:
GramediaPustaka Utama

Swastha, Basu dan Irawan.2008. Manajemen Pemasaran Modern. Yogyakarta: Liberty Offset

R.Terry, George dan Leslie W.Rue.2010. DasarDasar Manajemen. Jakarta: Bumi Aksara
Ulyah, Nadrotul. 2016.Analisis Strategi Pemasaran untuk Meningkatkan Penjualan Pada PT. Bhirawa Steel. Surabaya.Sekolah Tinggi Ilmu Ekonomi Perbanas Surabaya.

Wijaya, Olivia. 2017. Analisis Strategi Pemasaran Dalam Meningkatkan Volume Penjualan Pada PT. Sangga Buana Seputih Banyak Lampung Tengah. Bandar Lampung. Universitas Bandar Lampung.

Wulan, Sapmaya. 2012. Metode Penelitian Bisnis, digunakan untuk mahasiswa dilingkungan program studi Manajemen Fakultas Ekonomi Universitas Bandar Lampung.

Wibowo Emir Mohamad. 2018. Analisis Strategi Pemasaran Produk Sosis Siap Makan (Studi Kasus : PT Primafood Internasional). Sekolah Bisnis Institut Pertanian Bogor 